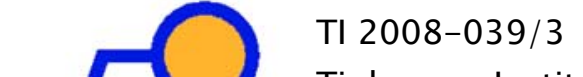

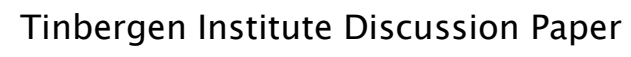 \\ The Role of Information in the Take- up of Student Loans
}

\author{
Adam Booij \\ Edwin Leuven \\ Hessel Oosterbeek
}




\section{Tinbergen Institute}

The Tinbergen Institute is the institute for economic research of the Erasmus Universiteit Rotterdam, Universiteit van Amsterdam, and Vrije Universiteit Amsterdam.

Tinbergen Institute Amsterdam

Roetersstraat 31

1018 WB Amsterdam

The Netherlands

Tel.: +31(0)205513500

Fax: $+31(0) 205513555$

Tinbergen Institute Rotterdam

Burg. Oudlaan 50

3062 PA Rotterdam

The Netherlands

Tel.: + $31(0) 104088900$

Fax: $+31(0) 104089031$

Most TI discussion papers can be downloaded at http://www.tinbergen.nl. 


\title{
The role of information in the take-up of student loans*
}

\author{
Adam Booij $\quad$ Edwin Leuven Hessel Oosterbeek
}

\begin{abstract}
Policies need not only to be well designed to effectively address market failures, but their parameters also need to be part of agents' information sets. This is illustrated by government student loans in the Netherlands which are intended to alleviate liquidity constraints. Despite generous loan conditions, take-up rates on these loans are low. Some have argued that this is due to limited knowledge about these conditions. We examine the importance of information constraints through a randomized experiment. Half of the students who responded to an Internet questionnaire were given factual information on loan conditions, whereas the other half did not receive such information. Six months later, students who received information have better knowledge about the loan conditions. While OLS regressions reveal a large and significantly positive association between knowledge about loan conditions and borrowing, our instrumental variable estimates suggest that this is not a causal effect which would rule out that the low take-up rate is caused by information constraints.
\end{abstract}

JEL-codes: I22; I28; D83

Keywords: Field experiment; Student debt; Student loans; Loan conditions

\section{Introduction}

Most developed countries substantially subsidize college enrollment through financial aid and subsidies to public institutions. When individuals seek to finance their education they will find it difficult to take out a commercial loan because of the absence of collateral and the presence of moral hazard. Financial aid in the form of grants or attractive loans are aimed at lifting credit constraints. There is however evidence that students underutilise

*This version: April 2008. The authors are affiliated with the Universiteit van Amsterdam School of Economics and the Tinbergen Institute. Leuven is also affiliated with the CEPR, CREST and IZA. We gratefully acknowledge valuable comments from seminar participants in Paris. 


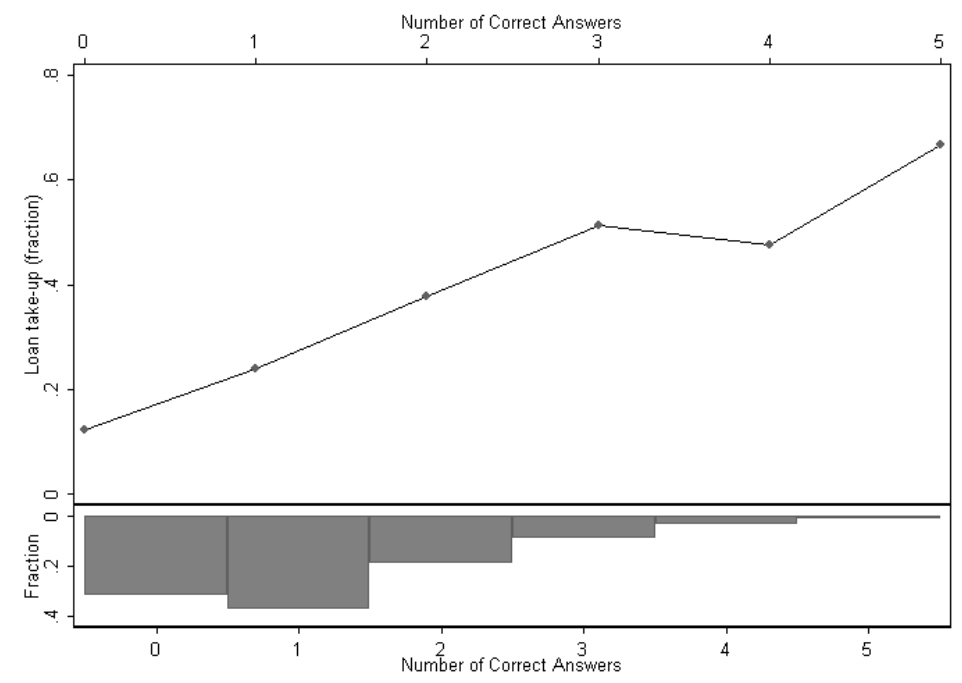

Figure 1: Knowledge about loan conditions and loan take-up rates

financing possibilities in the forms of loans. Some have suggested that this is due to "debt aversion" which occurs when having a debt lowers utility over and above its impact on life-time consumption patterns (e.g. Field 2006; Oosterbeek and Van den Broek 2008).

Another barrier to student loan take-up is information. If students are imperfectly or incorrectly informed about loan conditions take up rates on student loans will be suboptimal and may reduce investment in post-secondary education. In defense of a shift towards a more prominent role for loans, a former Dutch (vice-) minister responsible for higher education argued that instead of debt aversion, the key factor explaining the low take-up rate in the Netherlands (35\%) is the uninformedness of students about the generous loan conditions. He based this view on a study showing that students who are well informed about the loan conditions are also significantly more likely to have a student loan.

The top panel of Figure 1 shows the strong correlation between informedness and borrowing based on the data used in this paper. For every correct answer about the loan conditions the take-up rate increases by roughly ten percentage points. At the same time the bottom panel shows that indeed many students are rather poorly informed about the loan conditions (over $70 \%$ gives a correct answer to not more than one out of five questions). This suggests that by better informing students the overall take-up rate will increase. This will obviously not happen if the relation in Figure 1 arises because students who are more interested in taking a loan also gather more information about the loan conditions, or that those who have taken out such a loan receive information about the loan conditions.

We conducted a randomized experiment to estimate the causal effect of better knowledge about loan conditions on loan take-up. Randomly fifty percent of the students who responded to an Internet questionnaire were given factual information about loan condi- 
tions, whereas the other half did not receive such information. ${ }^{1}$ Half a year later, the respondents were interviewed again. Those who were exposed to treatment turn out to have significantly more accurate knowledge about loan conditions, thereby indicating that the supply of information has an impact on knowledge six months later. At the same time, exposure to the information treatment and possessing more accurate knowledge appears to have no impact on the loan take-up rate, thereby rendering the claim of the higher education (vice-) minister invalid.

This paper proceeds as follows. The next section provides more details of the student financial aid scheme in the Netherlands and the recent policy discussion related to that. Section 3 describes the experimental design and the empirical approach based on it. Section 4 introduces the data. Section 5 presents and discusses the empirical results. Section 6 summarizes and concludes.

\section{Background}

The student financial aid system run by the Dutch government consists of three components: (i) a basic grant provided to all students; (ii) an additional grant for students from low income families; and (iii) a student loan scheme with a mortgage type repayment. Although the system changed several times after its introduction in 1986 (Belot et al., 2004), these three components have been part of the loan scheme since the start.

In 2007, the year of this study, the basic grant equalled $€ 290$ per month, with an additional means-tested supplementary grant of $€ 250$ per month at maximum. Additionally, all students were allowed to borrow an additional amount until their total financial aid from the government equalled $€ 790$ euros at maximum. Hence, for students that do not receive the supplementary grant, the maximum loan amount was $€ 500$. The basic and supplementary grants are given for 4 or for 5 years, depending on the length of the curriculum. After this period there is an extended loan period of three years in which students can borrow a maximum of $€ 790$ per month.

If the student does not obtain a diploma within ten years, the received grants are transformed into a loan. The interest rate on the loan is equal to that of long term government bonds (3.7\% in 2007), which is well below individual borrowing rates in the Netherlands. ${ }^{2}$ Repayment of the total debt starts after a grace period of 2 years. The monthly repayment amount is calculated as an annuity such that the total debt is repaid in exactly 15 years.

\footnotetext{
${ }^{1}$ Another study which manipulates the amount of information in an experimental setting is Duflo and Saez (2003). They however, focus on the role of social interactions which do not play a role in this study since treated and controls are not connected.

${ }^{2}$ Before 1992 government student loans where interest free. This was changed to prevent students making a profit through arbitrage.
} 
However, the monthly installments are $€ 45$ at minimum. In months when monthly income is below a certain threshold the installment is forgiven. This implies that students with low future incomes will not repay their entire debt.

Compared to financial aid schemes in other countries, the Dutch scheme is rather generous. Few other countries provide basic grants to all students, and if they do the amounts are smaller (Usher and Cervenan, 2005). Also, only about half of the governments of OECD countries offer loan schemes to students, most of which contain no provision in case of low future incomes (Usher, 2005). Not surprisingly, the Dutch higher education system was ranked in the top three in terms of affordability in an international comparative study of 16 countries conducted by Usher and Cervenan (2005).

While the grant given to students in the Netherlands is large in comparison with grants given elsewhere, it is insufficient to cover living costs and education expenditures. Hence it could be expected that students would make use of the loans scheme to supplement their income, as is observed in other countries. In Sweden for example, where the government offers a basic grant of similar magnitude as in the Netherlands, more than $85 \%$ of students take a loan. Similar take-up rates are observed in other countries (Norway: 78\%, U.K.: 85\%, US: 50\%; see Vossensteyn, 2004; Usher, 2005). This figure has consistently been much lower in the Netherlands, where the take-up rate is around 35\% (Biermans et al., 2003; Van den Broek and Van de Wiel, 2005).

The low take-up rate is viewed as a problem in the Netherlands because students seem to work next to their study to avoid debt. Studies have found that on average Dutch students spend about 10 hours per week working in a job on the side (Biermans et al., 2003; Van den Broek et al., 2006). This is not desirable from the government's perspective because it is likely to lead to an increased study length. Kalenkoski and Pabilonia (2008); Oettinger (2005); Stinebrickner and Stinebrickner (2003) provide evidence that work during college has detrimental effects on study performance. Indeed the Netherlands has a poor record in this respect, with an average study duration of 6 years (excluding dropouts, CBS 2007) whereas the nominal duration of most higher education programs is 4 years. Since each student-year is heavily subsidized (Jongbloed et al., 2003), this is costly for the government.

To investigate the observed reluctance to borrow, the Dutch (vice-)minister of education called for research into students' attitudes and knowledge with respect to the loan scheme. A subsequent study found that, not only did students prefer working to supplement their income over borrowing, they also appeared to be only moderately informed about the loan scheme (Van den Broek and Van de Wiel, 2005). Moreover, students who were actually borrowing appeared to be better informed about the borrowing conditions than students who were not taking a loan. The same pattern was found in a similar study 
on borrowing of students in the UK (Callender, 2003). The policy recommendation in the Dutch report, that increasing student awareness of the loan conditions may increase borrowing, was soon echoed by the minister (Ministry of Education, 2006). However, it is not a priori clear that this association reflects the causal link implied by this recommendation. It may well be that taking a loan increases students' knowledge about the conditions but not vice versa.

\section{Experimental design and empirical strategy}

To isolate the causal impact of accurate knowledge about loan conditions on the loan take-up rate, we conducted a randomized experiment. A representative sample of Dutch higher education students were invited by E-mail to take part in two consecutive Internet surveys, with half a year in between (the first invitation did not announce the second questionnaire). The E-mail addresses were obtained from the Dutch agency that administers students' university enrollment, grants and loans. This agency also possesses respondents' background information on variables such as age, gender and Socio-Economic Status (SES).

The first questionnaire, sent out in February 2007, came in two versions. The entire sample of students received questions about their opinions concerning student loans and past borrowing. In addition, (a randomly assigned) half of the sample received factual information about five loan conditions. This information was presented in the form of questions that asked respondents how favorable they thought each condition was. More specifically, these students were asked how favorably they perceived the following conditions:

1. The maximum loan amount during the grant period (which equals $€ 500$ )

2. The maximum loan period after the grant period (which equals 36 months)

3. The grace period (which equals 2 years)

4. The maximum length of the repay period (which equals 15 years)

5. The interest rate on student loans (which equals 3.7\%)

The main reason to present the factual information in the form of questions was to give respondents a reason to read and think about the information. The respondents that received the version with the factual information about the loan conditions are in the treatment group, while the respondents that received the version without the factual information constitute the control group. 
The follow-up survey, administered six months later in August 2007, asked the respondents to the first questionnaire again to fill in an Internet questionnaire. This questionnaire was identical for the treatment and control groups. Questions were asked about respondents' current study situation, their perceptions on job prospects, their attitudes towards borrowing, risk taking attitudes and the amount they borrowed in each of the months following the first survey.

Furthermore, questions were asked to measure respondents' knowledge about the loan conditions. In particular, they were asked what they thought were the true values of the five conditions about which the treatment group received information in the first questionnaire. It was stated explicitly that they should not search for this information on the Internet or elsewhere, stressing that giving a wrong answer would be without any consequence and that we were only interested in getting a picture of students' overall awareness about the loan conditions. We consider the fact that only a handful of respondents answered all five questions correctly ( 3 in the control group, 2 in the treatment group) as evidence that (almost) no one searched for the correct answers.

The intention behind this research design is that the random assignment of the information treatment generates exogenous variation in respondents' knowledge about the loan conditions and that this variation can then be used to estimate the impact of more accurate knowledge of loan conditions on the loan take-up rate using an instrumental variable approach, where the treatment is used as an instrument for the accuracy of knowledge about the loan conditions.

The outcome variable of interest is a binary variable (denoted by $y_{i}$ ) that equals 1 if student $i$ took a loan in the four months after the first survey, and 0 otherwise. This variable is related to characteristics such as family background, type of study, previous loan experience, and most importantly, the student's knowledge about the loan conditions. This variable, written as $K_{i}$, is operationalized as the number of questions about loan conditions the student answered correctly in the follow-up survey. Imposing a linear relationship, we can write:

$$
y_{i}=\alpha K_{i}+x_{i}^{\prime} \beta+u_{i}
$$

where $x_{i}$ collects control variables and $u_{i}$ denotes an error term. The effect of interest is $\alpha$. Estimation of this parameter using OLS will be biased if $K_{i}$ is correlated with $u_{i}$, which would for instance be the case if students who are more interested in taking up a loan also collect more information, or acquire more knowledge because they borrow (in which case $\alpha$ picks up a reverse causality).

To estimate the causal impact of $K_{i}$ on $y_{i}$ we instrument $K_{i}$ with the treatment dummy $T_{i}$, which equals 1 for students who were exposed to the information treatment and 0 for students who were assigned to the control group. To this end we estimate the following 
first stage equation:

$$
K_{i}=\gamma T_{i}+x_{i}^{\prime} \delta+\eta_{i}
$$

where $\eta_{i}$ is an error term. The standard conditions that need to be fulfilled in order to use the treatment indicator $T_{i}$ as an instrumental variable for knowledge $K_{i}$ are: (i) that $T_{i}$ has an impact on $K_{i}$, and (ii) that $T_{i}$ is uncorrelated with $u_{i}$ conditional on $x_{i}$. The first condition can be tested, and our first stage estimations of equation (2) show that it is indeed fulfilled. In general the second condition cannot be tested, but since the information treatment was assigned randomly, we can be confident that this condition also holds. To support this, the next section presents results showing that treatment status is uncorrelated with observable characteristics.

\section{Data}

A total of 3,812 students responded to the first questionnaire in which they were asked about their field and level of study, and about their attitudes towards borrowing. About half of this sample $(N=1,914)$ randomly received information about the properties of student loans provided by the government. All students that completed the first survey were contacted again for the follow-up survey. The response rate for this second survey was $61 \%$, which is comparable to other studies that target this sample and quite reasonable considering that it was conducted at the end of the summer holiday. Response rates were virtually identical for the treatment and control groups (61\% and $60 \%$ respectively). Hence, there is no indication of selective non-response with respect to treatment.

Table 1 reports descriptive statistics of the background variables that will be used as control variables. These descriptives are reported separately for the treatment and control groups. The important result in this table is that there are no significant differences between the groups for any of the variables. This indicates - as we claimed above - that the randomization worked.

The mean values for age, social background and ethnicity are comparable to those in the population of higher education students. Two preference parameters that play a central role in economic models of investment decisions under uncertainty are risk aversion and the subjective discount rate. Risk aversion is measured by a subjective self evaluating measure of risk attitudes on a 1 to 10 scale that increases in risk tolerance. A series of hypothetical intertemporal choices pin down individuals' subjective discount rate. The students are, on average, moderately risk tolerant (6/10) and also moderately impatient (20\%). These numbers are comparable with Dohmen et al. (2006) and Harrison et al. (2002), who find 5/10 and 28\% for the German and Danish populations, respectively.

The variable "loan experience" indicates whether the student had taken up a student 
Table 1: Descriptive Statistics

\begin{tabular}{lrrrrrrrr}
\hline & \multicolumn{2}{c}{ Controls } & & \multicolumn{2}{c}{ Treated } & & \\
\cline { 2 - 3 } & Mean & s.d. & & Mean & s.d. & Difference & $p$-value \\
\hline Female & 0.67 & 0.47 & & 0.65 & 0.48 & -0.018 & 0.386 \\
Age & 21.07 & 1.81 & & 21.04 & 1.72 & -0.031 & 0.684 \\
Ethnic minority & 0.05 & 0.21 & & 0.04 & 0.20 & -0.004 & 0.653 \\
SES & 2.52 & 1.39 & & 2.53 & 1.38 & 0.004 & 0.941 \\
Discount rate & 0.21 & 0.19 & & 0.21 & 0.19 & -0.002 & 0.824 \\
Risk tolerance & 5.67 & 2.05 & & 5.65 & 2.10 & -0.016 & 0.859 \\
Academic track & 0.60 & 0.49 & & 0.62 & 0.49 & 0.014 & 0.508 \\
Loan experience & 0.30 & 0.46 & & 0.30 & 0.46 & -0.004 & 0.838 \\
$N$ & 1,090 & & & 1,098 & & & \\
\hline
\end{tabular}

Note: Mean values with standard deviations in parentheses. $p$-values are based on $t$-tests.

loan prior to the first survey. In both groups this fraction equals $30 \%$, which is similar to what is reported in other studies (Biermans et al., 2003; Van den Broek et al., 2006). Hence, the sample reflects the observation that loan take-up is low in the Netherlands compared to other western countries (Usher, 2005).

As discussed above, we operationalized students' knowledge about the loan conditions by the number of questions the student answered correctly. To compare the answers to the true value, we rounded them to the unit which seemed to match the response scale for most respondents. The maximum loan amount ( $€ 500)$ for example was rounded to hundreds of euros, and the other questions were rounded to appropriate scales in a similar way. ${ }^{3}$ This rounding clarifies our graphical analyses (below) and does not affect the results since the correlation between the true and the rounded value is never below 0.99 .

To better understand which students make use of student loans, the first column of Table 2 presents estimates from a linear probability model where loan experience is regressed on student characteristics. There are no differences between boys and girls, and older students are more likely to borrow. Interestingly, students who are more at risk of being liquidity constrained, that is students with an ethnic minority background and students from lower socio-economic backgrounds, are not more likely to have taken out a student loan. One explanation is that the means tested component of the Dutch grant scheme adequately compensates students for their financial background. Finally, the most important determinants of loan experience seem to be students' discount rate and risk attitude

\footnotetext{
${ }^{3}$ The maximum loan period after the grant period (36 months) was rounded to years, the maximum length of the repay period ( 15 years) was rounded to 5 years, and the interest rate ( 3.7 percent) was rounded to half a percentage point around the true value. The grace period was not rounded since all respondents answered in whole years.
} 
Table 2: Student characteristics, loan experience and loan knowledge (OLS)

\begin{tabular}{|c|c|c|c|c|}
\hline & \multicolumn{2}{|c|}{ Loan Experience } & \multicolumn{2}{|c|}{ Loan Knowledge } \\
\hline & \multicolumn{2}{|r|}{ (1) } & \multicolumn{2}{|r|}{ (2) } \\
\hline Female & 0.003 & $(0.021)$ & -0.010 & $(0.049)$ \\
\hline Age & 0.040 & $(0.007)^{* * *}$ & 0.031 & $(0.015)^{*}$ \\
\hline Ethnic minority & -0.006 & $(0.047)$ & -0.113 & $(0.101)$ \\
\hline Socio-Economic Status & & & & \\
\hline - Level 2 & 0.026 & $(0.025)$ & -0.047 & $(0.059)$ \\
\hline - Level 3 & -0.034 & $(0.031)$ & -0.058 & $(0.079)$ \\
\hline - Level 4 & 0.072 & $(0.033)^{* *}$ & 0.009 & $(0.077)$ \\
\hline - Level 5 & -0.004 & $(0.032)$ & 0.078 & $(0.077)$ \\
\hline Academic track & 0.049 & $(0.021)^{* *}$ & 0.286 & $(0.049)^{* * *}$ \\
\hline Study duration (moths) & 0.011 & $(0.011)$ & 0.123 & $(0.027)^{* * *}$ \\
\hline Discount rate & 0.194 & $(0.054) * * *$ & 0.145 & $(0.126)$ \\
\hline Risk tolerance & 0.016 & $(0.005) * * *$ & 0.019 & $(0.011)^{*}$ \\
\hline Intercept & -0.710 & $(0.128)^{* * *}$ & -0.058 & $(0.304)$ \\
\hline
\end{tabular}

It is also useful to consider how well different students are informed about the loan conditions. In the second column of Table 2 the number of correct answers on the five questions on loan conditions were regressed on the same student characteristics as in column (1). Students in the academic track are better informed, as are older and more experienced students. Risk averse students are also better informed. Again there is no relation between both socio-economic status and ethnicity, and loan knowledge.

Table 2 shows that the most important determinants of borrowing are students' discount rates and risk attitudes. There is no indication that liquidity constrained students are more likely to borrow. The results in the table suggest that this could be due to the fact that these students are not better informed about the loan conditions in the Netherlands than students from more favorable backgrounds, an explanation we will investigate in the next section.

\section{Results}

This section presents the empirical results of our experiment. It starts with reporting the impact of the information treatment on knowledge about loan conditions. It then presents results from OLS regressions of borrowing behavior on knowledge about loan conditions, the (reduced form) effect of exposure to the information treatment on borrowing behavior, and finally the IV-estimates of the impact of more accurate knowledge about loan conditions on borrowing behavior. 
Table 3: Mean responses to questions about loan conditions, by treatment status

\begin{tabular}{lrrrrrrrr}
\hline & \multicolumn{2}{c}{ Controls } & & \multicolumn{2}{c}{ Treated } & & \\
\cline { 2 - 3 } & Mean & s.d. & & Mean & s.d. & Difference & $p$-value \\
\hline Max loan & 422.8 & 213.6 & & 448.2 & 210.8 & 25.4 & 0.005 \\
Max loan period & 21.2 & 19.4 & & 23.3 & 18.8 & 2.1 & 0.012 \\
Grace period & 4.9 & 3.4 & & 5.0 & 3.4 & 0.1 & 0.597 \\
Repay period & 14.5 & 10.5 & & 13.8 & 7.5 & -0.7 & 0.057 \\
Interest rate & 2.6 & 1.8 & & 2.7 & 1.8 & 0.1 & 0.083 \\
$N$ & 1,090 & & & 1,098 & & & \\
\hline
\end{tabular}

Note: Mean values with standard deviations in parentheses. $p$-values are based on $t$-tests.

\subsection{The impact of the information treatment on knowledge about loan conditions}

Before turning to our discussion of the impact of knowledge about loan conditions on loan take-up we need to assure that exposure to the information treatment has an impact on students' knowledge. The follow-up survey asked students about their knowledge about five loan conditions, and Table 3 reports for each condition the mean responses of the students in the treatment and control groups, and their differences.

The results in column (1) show that Dutch higher education students (represented by the control group) are indeed poorly informed about the loan conditions. They underestimate the size of the maximum loan by over 75 euros (by more than 15\%), underestimate the maximum loan period by over one year (by more than a third), overestimate the maximum grace period by almost 3 years $(150 \%)$, underestimate the maximum repayment period by less than half a year (less than $4 \%$ ), and underestimate the interest rate by more than 1 percentage point (almost $30 \%$ ).

Notice that the poor information of students in the control group is not always in the direction of regarding the loan conditions as less generous than they actually are, as illustrated by the fact that students both overestimate the grace period and underestimate the interest rate.

Comparing the results in column (1) to those in column (2) shows that students who were exposed to the information treatment have on average more accurate knowledge about the size of the maximum loan, about the maximum loan period and about the interest rate than students in the control group. Students in the control group have, however, on average more accurate knowledge regarding the maximum grace period and the maximum repayment period. This mixed picture casts some doubt on the effectiveness of the information treatment.

Comparing the averages to the true values is misleading however, because that does not properly account for the full difference in the distribution. Figure 2 displays his- 

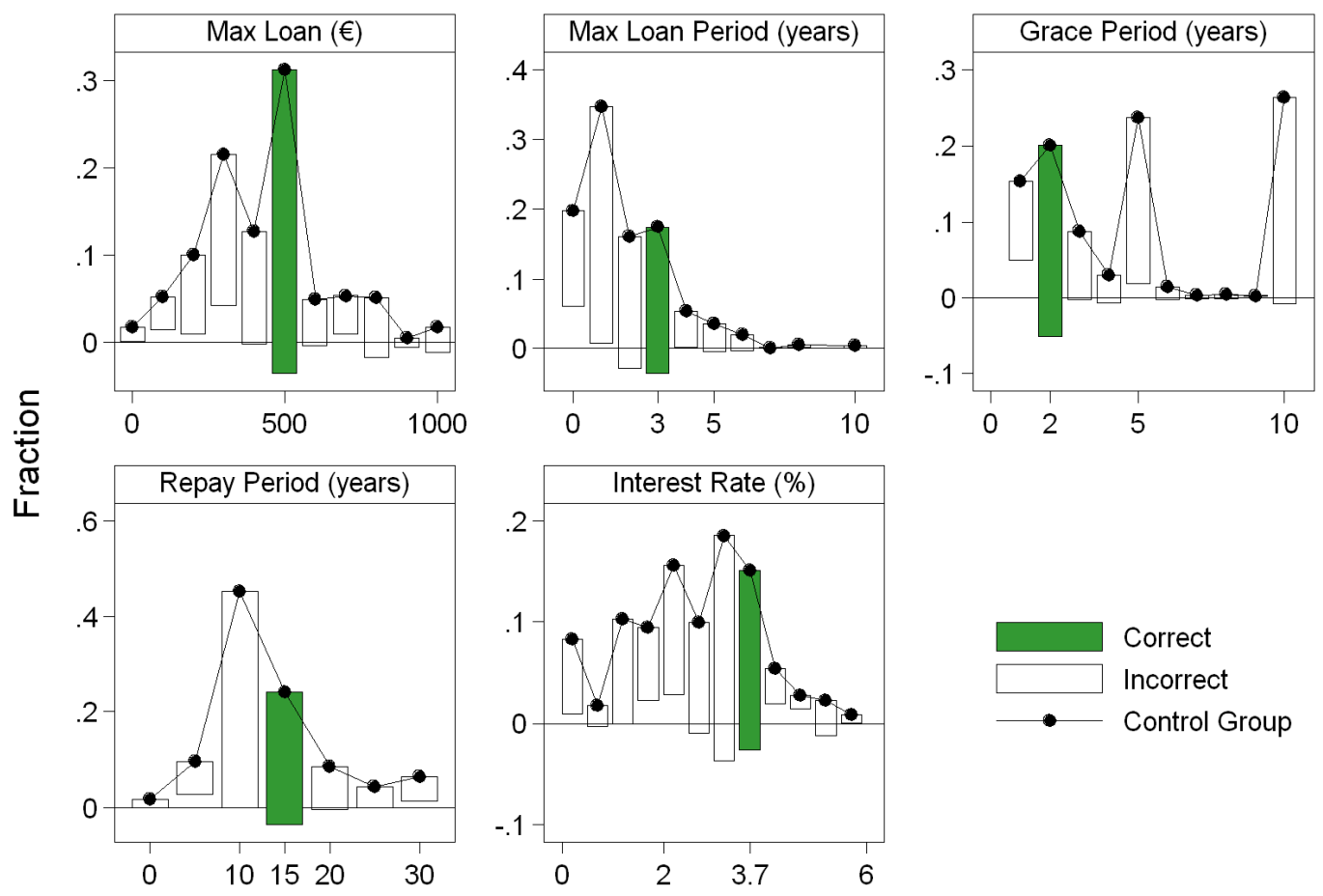

Figure 2: Students' perceptions of loan conditions

tograms of the perceptions of both the treated (vertical bars) and controls (connected points) for all conditions. The bars of the treated are "hanging" from the line spanned by the controls, such that the bars crossing the $\mathrm{x}$-axis at zero indicate a higher concentration among the treated at that value.

Since the bars of the true values are shaded it is easy to see that there is a higher concentration of answers close to the correct value for the treated than the controls. For all conditions the treated bars are sticking out at the true value, meaning that the treated have better perceptions. This does not follow from the shifts in the averages because the distribution relocation is asymmetric around the true value. Hence it is possible for the average to move in the wrong direction while the fraction of informed people, the shaded column, increases.

The effects of the treatment on correctly answering the questions about the loan conditions are displayed in Table 4. For most conditions the treatment increases the group of correctly informed students by about 4 percentage points. The effect is strongest for the grace period $(5.1 \%)$, and weakest for the interest rate $(2.4 \%)$. Judging from Figure 2 however, it is clear that also for the latter condition the probability mass shifts to values closer to the true value. In total the controls answer on average 1.07 questions correctly, while the treated manage 1.26 . Hence knowledge increases by about $18 \%$, a moderate but 
significant change.

The information treatment has the strongest bearing on (total) knowledge. Effectively, all the variation in the treatment response of the different loan-conditions is collected by this measure, generating an F-statistic of 15.1. This number satisfies the rule of thumb of $F>10$ that is often used to gauge the risk of small sample bias caused by a weak instrument (Staiger and Stock, 1997). However, the (partial) explanatory power of the instrument, given by the partial R-squared measure equals 0.007 , which is not very high. This will furtger inflate the IV standard errors compared to those of OLS. The precision of the estimates may be increased if we select a sub-group for which the instrument has more power (see, for example, Black et al., 2005). In particular, it seems likely that the effect of information will be smaller for students who have prior loan experience. These students have already encountered the loan scheme, and may thus be expected to have some knowledge about it. Hence, there may be less scope for improvement for this group of students. To investigate this, we break down the first stage by prior loan experience. The results are presented in the middle and bottom panels in Table 4.

For the aggregate measure of "Correct answers", the point estimate drops from 0.18 to 0.12 and turns insignificant for the group of students that have prior loan experience. The partial F-statistic is only 1.76. This is partly caused by the reduction in sample-size, but if we look at the explained variance we find the same: the power of the instrument is severely reduced, from 0.007 to 0.002 , if the sample is restricted to students with prior loan experience. In contrast, for the group of students without loan experience the point estimate is now 0.21 and the explanatory power increases to 0.01 . Apparently, inexperienced students are particularly affected by the treatment, which is the group of students that would be specifically targeted by an information campaign and for whom we may hope for the largest effects. Hence, in what follows we will show a break down by loan experience.

\subsection{Borrowing behavior and knowledge about loan conditions}

Column (1) in Table 5 reports the OLS estimates of the relation between borrowing behavior and knowledge about the loan conditions for the full sample, and for the groups with and without prior loan experience. In all three cases, we observe a substantial and significant relation. Each additional correct answer is associated with an increase in the probability that a student has a loan of 8 to 9 percentage points. This result reiterates the pattern observed in Figure 1. But just like in Figure 1, this relation needs not be causal.

Exposure to the information treatment has a significant effect on knowledge, especially for target group of students without loan experience. Whether exposure to the information treatment also translates into an increase in borrowing is displayed in column 


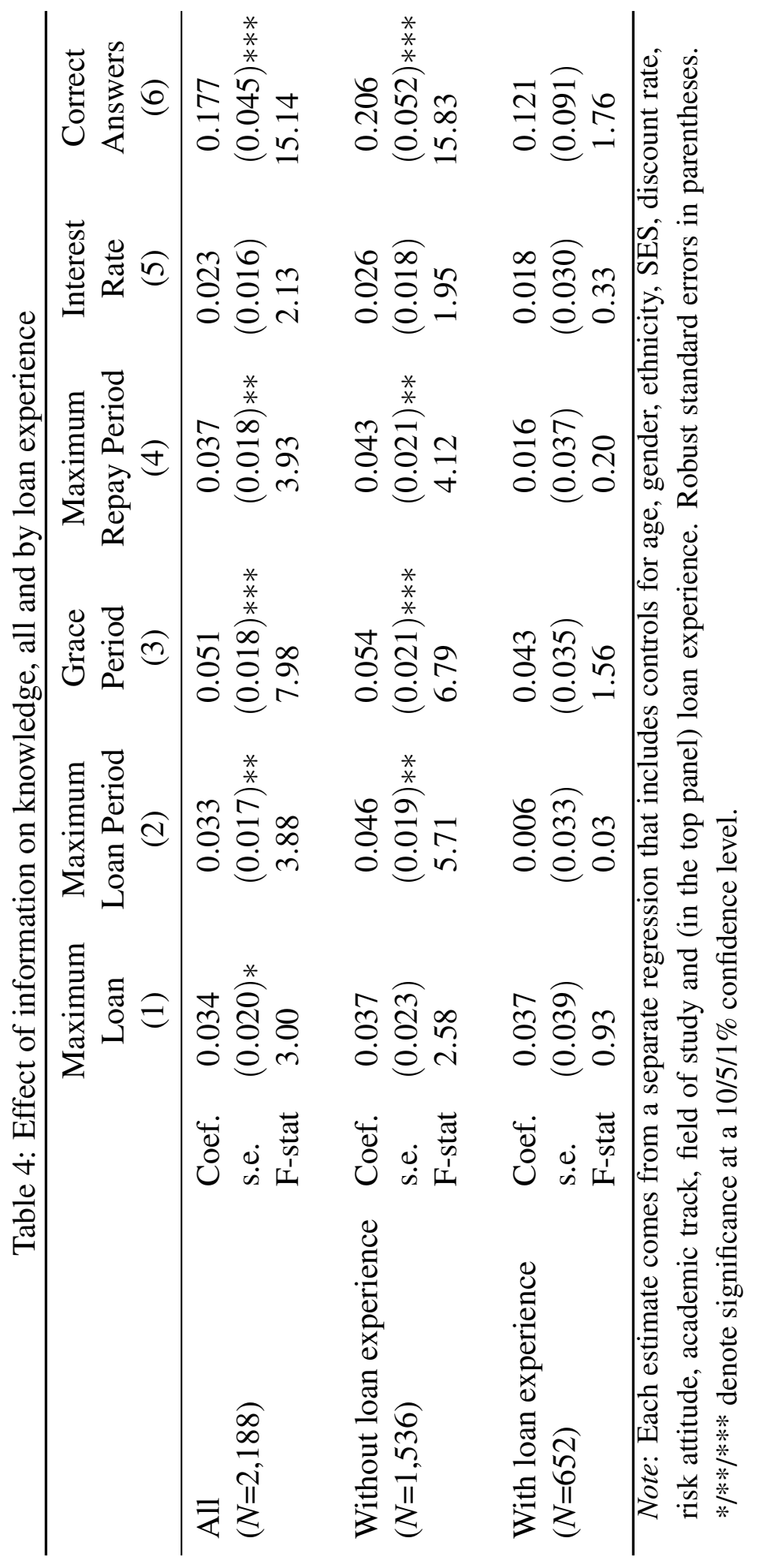


Table 5: The effects of treatment and knowledge on borrowing behavior - OLS, Reduced Form (RF) and IV

\begin{tabular}{lccc}
\hline & OLS & RF & IV \\
& $(1)$ & $(2)$ & $(3)$ \\
\hline All & 0.086 & 0.004 & 0.022 \\
& $(0.008) * * *$ & $(0.017)$ & $(0.092)$ \\
No Loan Experience & 0.081 & -0.015 & -0.071 \\
& $(0.010) * * *$ & $(0.017)$ & $(0.089)$ \\
Loan Experience & 0.094 & 0.037 & 0.309 \\
& $(0.016) * * *$ & $(0.038)$ & $(0.338)$ \\
\hline
\end{tabular}

Note: Each estimate comes from a separate regression that includes controls for age, gender, ethnicity, SES, discount rate, risk attitude, academic track, field of study and (in the first three columns) loan experience. Robust standard errors in parentheses. $* / * * / * * *$ denote significance at a $10 / 5 / 1 \%$ confidence level.

(2) in Table 5. For the whole sample the estimated effect is 0.004 , and not significantly different from zero. Interestingly, there is a divide in the effect if we consider the break up by loan experience. The point estimate is negative for the inexperienced borrowers ($0.015)$ and positive for those that have encountered loans before (0.037). This difference is not significant, but it suggests that the effect may even be negative for the target group.

The ratio of the reduced form and the first stage estimates gives the instrumental variable estimate of the causal effect of knowledge on borrowing behavior. The estimates are presented in column (3) in Table 5. For the whole sample the IV estimate equals 0.022 , which is with a standard error of 0.092 not significantly different from zero. Unfortunately, however, this standard error is so large that we can also not reject that the IV estimate is equal to the OLS estimate. For the group of students without prior loan experience the IV-estimate equals -0.071 and with a standard error of 0.089 is not significantly different from zero. We reject equality of the OLS and IV-estimates; the IV-estimate is significantly below the OLS estimate $(p$-value $=0.042$ ). For completeness the table also reports the IV-estimate for the group of students with prior loan experience, but since we have a weak instrument for this group the design is not informative here.

We have estimated the effect of being correctly informed about student loan conditions on their take up. Although our estimates are relatively imprecise they suggest that informing students about loan conditions may even lower take up rates. The explanation may lie in the fact that the treatment may result in "positive" or "negative" information updates. That is, the treatment may lead to more or less favorable perceptions of the actual loan conditions. The estimated effect of the treatment will therefore be an average 
of these two possibly offsetting effects which can explain the negative point estimates in Table 5.

\section{Summary and discussion}

The effectiveness of public policies is limited by the extent to which agents are correctly informed about them. Several studies document that students are poorly informed about the conditions of the government student loan scheme in the Netherlands. Students who are better informed have higher take-up rates. This suggests that governments can stimulate borrowing and thereby increase efficiency by providing more information about the supposedly favorable - conditions of their loan schemes. This is actually what the Dutch government has recently been considering.

To investigate whether there really exists a causal impact of better knowledge about loan conditions on borrowing behavior, we conducted a randomized experiment where half of the participants were exposed to an information treatment. Six months later we find that students who received information have better knowledge about the loan conditions. While for students with prior loan experience our treatment has no effect, for students without prior loan experience - which is the main target group of an information campaign - our design is informative.

Naive OLS estimates reveal a significantly positive association between knowledge about loan conditions and borrowing. This is consistent with the findings of earlier studies. Our instrumental variable estimates suggest, however, that there is no causal impact of better knowledge on borrowing, thereby indicating that information provision is an ineffective method to increase the loan take-up rate. Although this may imply that the loan scheme is effective in lifting liquidity constraints, the results of our experiment do not answer the question why Dutch higher education students have low take-up rates on study loans. They merely reject uninformedness about the favorable loan condition as a valid explanation. Although the results suggest that the information constraint is not binding other constraints may be, and subsequent studies should therefore focus on alternative explanations for low take-up rates such as debt aversion or the low returns to studying hard. The results of such studies can only be satisfactory if they also explain why borrowing rates are lower in the Netherlands than elsewhere.

\section{References}

Belot, M., Canton, E., and Webbink, D. (2004). Does Reducing Student Support Affect Educational Choices and Performance?: Evidence from a Dutch Reform. CPB Nether- 
lands Bureau for Economic Policy Analysis.

Biermans, M., de Graaf, D., de Jong, U., van Leeuwen, M., and der Veen, I. V. (2003). Leengedrag van studenten in het hoger onderwijs. Amsterdam: SEO/SCO-Kohnstamm Instituut.

Black, S. E., Devereux, P. J., and Salvanes, K. G. (2005). Why the apple doesn't fall far: Understanding intergenerational transmission of human capital. American Economic Review, 95:437-449.

Callender, C. (2003). Attitudes to debt. Technical report, London: Universities UK. Available at: www.UniversitiesUK.ac.uk/studentdebt.

Dohmen, T., Falk, A., Huffman, D., Schupp, J., Sunde, U., and Wagner, G. (2006). Individual risk attitudes: New evidence from a large, representative, experimentally validated survey. Discussion papers 5517, CEPR.

Duflo, E. and Saez, E. (2003). The role of information and social interactions in retirement plan decisions: Evidence from a randomized experiment. Quarterly Journal of Economics, 119:815-842.

Field, E. (2006). Educational debt burden and career choice: Evidence from a financial aid experiment at nyu law school. Working Paper No. W12282, NBER.

Harrison, G., Lau, M., and Williams, M. (2002). Estimating individual discount rates for denmark: A field experiment. American Economic Review, 92:1606-1617.

Jongbloed, B., Salerno, C., and Kaiser, F. (2003). Kosten per student: Methodologie, schattingen en een internationale vergelijking. Technical report, Enschede: CHEPS.

Kalenkoski, C. M. and Pabilonia, S. W. (2008). Parental transfers, student achievement, and the labor supply of college students. BLS Working Paper 416.

Ministry of Education (2006). Rutte wil betere voorlichting over studieleningen. Technical report, Press communication Dutch ministry of Education (OCW). Available at: http://www.minocw.nl/actueel /persberichten/11958.

Oettinger, G. S. (2005). Parents' financial support, students' employment, and academic performance in college. Technical report.

Oosterbeek, H. and Van den Broek, A. (2008). An empirical analysis of borrowing behaviour of higher education students in the netherlands. Economics of Education Review, Forthcoming. 
Staiger, D. and Stock, J. H. (1997). Instrumental variables regression with weak instruments. Econometrica, 65(3):557-586.

Stinebrickner, T. and Stinebrickner, R. (2003). Working during school and academic performance. Journal of Labor Economics, 21(2):473-491.

Usher, A. (2005). Global debt patterns: An international comparison of student loan burdens and repayment conditions. Technical report, Toronto, ON: Educational Policy Institute.

Usher, A. and Cervenan, A. (2005). Global higher education rankings 2005. Technical report, Toronto, ON: Educational Policy Institute.

Van den Broek, A. and Van de Wiel, E. (2005). Leengedrag van studenten. Technical report, Nijmegen: ITS.

Van den Broek, A., Van de Wiel, E., Pronk, T., and Sijbers, R. (2006). Studentenmonitor 2005. Technical report, Nijmegen: ITS.

Vossensteyn, H. (2004). Student financial support: An inventory in 24 european countries. Technical report, Enschede: CHEPS. 